\title{
Grating coupled photonic crystal demultiplexer with integrated detectors on InP- membrane
}

\author{
F. Van Laere, D. Van Thourhout and R. Baets \\ Department of Information Technology-INTEC \\ Ghent University-IMEC \\ Ghent, Belgium \\ frederik.vanlaere@intec.ugent.be
}

\author{
T. Stomeo and T.F. Krauss \\ School of Physics and Astronomy \\ University of St. Andrews \\ St. Andrews, UK
}

\author{
M. Ayre, C. Cambournac and H. Benisty \\ Labaratoire Charles Fabry de l’Institut d'Optique \\ Univ. Paris Sud \\ Palaiseau, France
}

\author{
R. Brenot, \\ Alcatel Thales III-V lab \\ Palaiseau, France
}

\begin{abstract}
We report on the successful integration of grating fiber couplers, compact photonic crystal demultiplexers and efficient p-i-n photodetectors on a single bonded InPmembrane chip. Polarization independent operation is obtained by implementing polarization diversity.
\end{abstract}

Keywords-component; InP-membrane; photonic crystal; grating coupler; photodetector.

\section{INTRODUCTION}

Integration and miniaturization is the route towards ultradense integrated circuits at an acceptable price. Silicon-onInsulator (SOI) is emerging as an interesting platform for realizing very compact photonic components, due to its high refractive index contrast [1-2]. However, active functionalities remain awkward on silicon. Therefore, an attractive approach is to combine the membrane-based approach (high refractive index contrast) with the active functionality of InP.

In this paper, we present experimental results for a graded suite of compactly integrated InP-membrane devices, suited for application in Coarse WDM metro-networks. The core device is a compact photonic crystal demultiplexer on InP-membrane, with integrated p-i-n photodetectors. Light is coupled from the fiber to the device using compact grating couplers [3-4], which can also implement polarization diversity.

\section{BCB-BONDED INP-MEMBRANES}

Standard InP/InGaAsP heterostructures have a limited vertical refractive index contrast. In order to achieve the high vertical index contrast, needed for compact devices we exploit BCB wafer bonding [5]. A patterned InP-die is therefore bonded, with the epi-layers down, onto a host-substrate using the polymer BCB. After curing of this BCB, the original InPsubstrate is lapped and etched away. The resulting basic structure is a thin InP-membrane (in our case $300 \mathrm{~nm}$ ) surrounded by low-index material (air and BCB ( $\mathrm{n}=1.54$ at $\lambda=1.55 \mu \mathrm{m})$ ), as shown in Figure 1 .

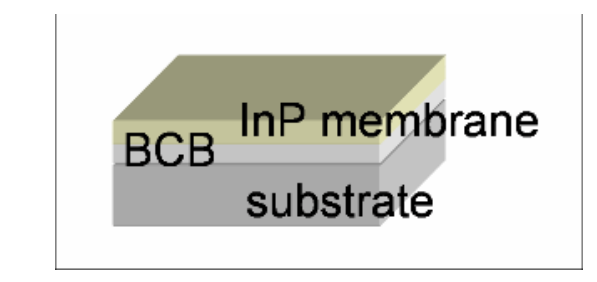

Figure 1. InP membrane obtained by BCB wafer bonding.

\section{GRATING COUPLED PHOTONIC CRYSTAL DEMULTIPLEXER}

We have implemented an ultra-compact photonic crystal (PhC) based demultiplexer on InP-membrane, for application in coarse WDM systems. The device is the first membrane version of the demultiplexer previously described in [6] for conventional InP heterostructures. It exploits the modal conversion at mini-stopbands (MSB) in a multimode photonic crystal waveguide (W5 in our case). SEM-pictures of the device prior to bonding are shown in Figure 2.

Light is coupled (near) vertically from a fiber into a membrane waveguide using grating couplers [3-4]. This signal feeds into a multimode photonic crystal waveguide. The fundamental mode couples to a higher order mode only in the MSB. The higher order mode is extracted by thinning one of the photonic crystal walls to a few rows of holes. Wavelength selectivity is obtained by varying the width of the $\mathrm{PhC}$ guide, which determines the central frequency of the MSB.

We have measured the device, consisting of 7 wavelength channels, spaced by $10 \mathrm{~nm}$. The light at the output channels is 


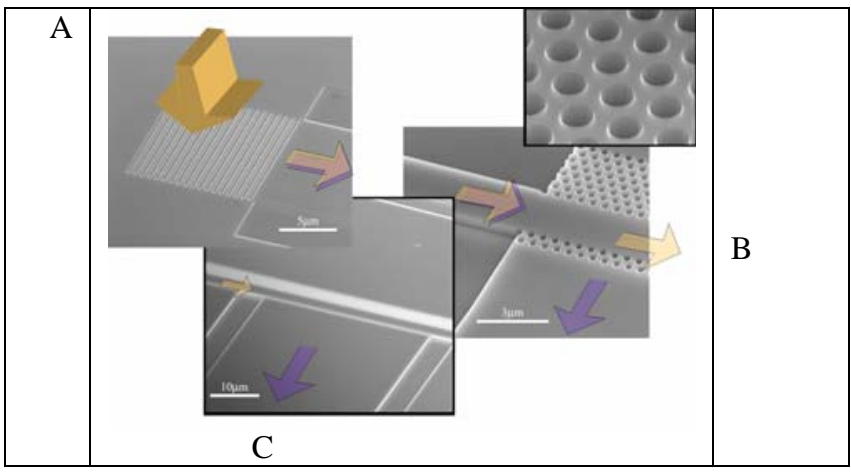

Figure 2. Grating coupled photonic crystal demultiplexer (prior to bonding). Light launched from a cleaved fiber is incoupled to a broad guide (A), tapered to a thin guide and enters the selective PhC guide (B). Demultiplexed signals are extracted through a thinned $\mathrm{PhC}$ wall.

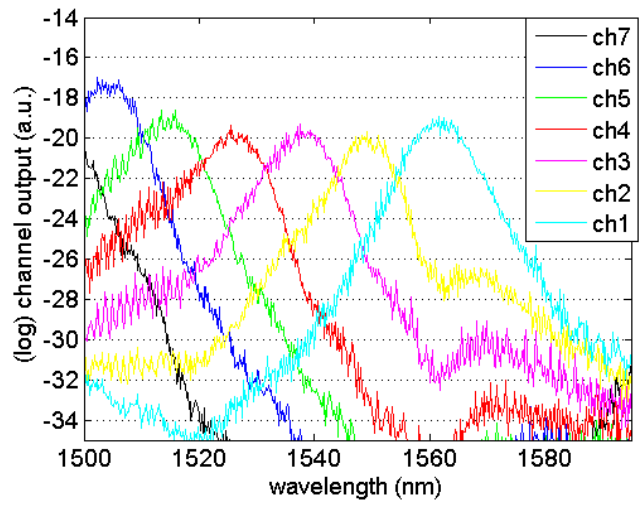

Figure 3. Measured channel output from the PhC demultiplexer.

collected at a cleaved facet. The crosstalk between adjacent CWDM channels (whose spacing is $20 \mathrm{~nm}, \Delta(\# \mathrm{ch})=2$ in Fig.3) is 7-8 dB. Measured spectra are shown in Figure 3.

\section{INTEGRATION OF DETECTORS ON INP-MEMBRANE}

We worked out a detailed integration scheme for integrating $\mathrm{p}$-i-n photodetectors onto the InP-membrane platform. A simulation of the designed detector structure is shown in Figure 4. Light from an InP-membrane waveguide (left on the figure) is coupled to an underlying absorbing InGaAs layer within a length adequate for most other purposes (speed, diversity scheme compatibility, sensitivity, width).

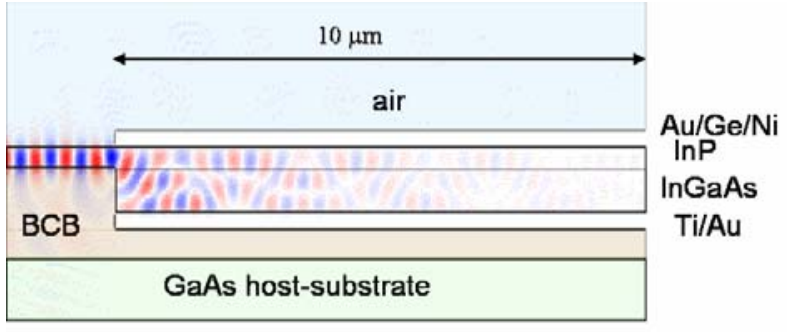

Figure 4. Eigenmode expansion simulation of a p-i-n detector integrated on an InP-membrane platform at $1550 \mathrm{~nm}$ central wavelength.
The layer structure consists of (from top to bottom) a $80 \mathrm{~nm}$ highly p-doped InGaAs layer, a $500 \mathrm{~nm}$ intrinsic InGaAs layer, a $300 \mathrm{~nm}$ (slightly) n-doped InP-membrane layer, a $500 \mathrm{~nm}$ InGaAs etch-stop layer on an InP-substrate. Pictures of the sample at different stages of the processing are shown in Figure 5. First, detector mesa's are defined using optical lithography and etching until the InP-membrane layer is reached. In the following step, gratings and waveguides are defined, aligned to the detector mesa's, using e-beam lithography. This pattern is etched to a depth of $90 \mathrm{~nm}$ into the InP-membrane layer. Large vias $\left(50 \times 50 \mu \mathrm{m}^{2}\right)$ are defined using optical lithography, and etched completely through the InP-membrane layer (300 nm). A picture of this structure is shown in Fig. 5(a-b). In the next step, a $700 \mathrm{~nm}$ BCB layer is spin coated onto the sample for passivation. After curing of the BCB, p-contact windows are opened, and a Ti/Au $(20 \mathrm{~nm} / 200 \mathrm{~nm}) \mathrm{p}$-contact, also covering the via, is deposited using lift-off (Fig. 5c). The die is then flipped and bonded onto a GaAs host-substrate using another (approximately $1 \mu \mathrm{m}$ thick) BCB layer (Fig. $5 \mathrm{~d}$ ). After curing for 1 hour at $250^{\circ} \mathrm{C}$ in a nitrogen environment, the InPsubstrate is removed (using lapping and wet etching) until the etch-stop layer is reached. Then, the etch stop layer is removed using wet etching. Finally, another passivation BCB layer is spin coated onto the sample. After curing, n-contact windows are opened and the access to the bottom p-contact is provided by etching the via (now filled with BCB) until the p-contact. Finally a $\mathrm{Au} / \mathrm{Ge} / \mathrm{Ni} \mathrm{n}$-contact is deposited using lift-off (Fig. 5e-f).
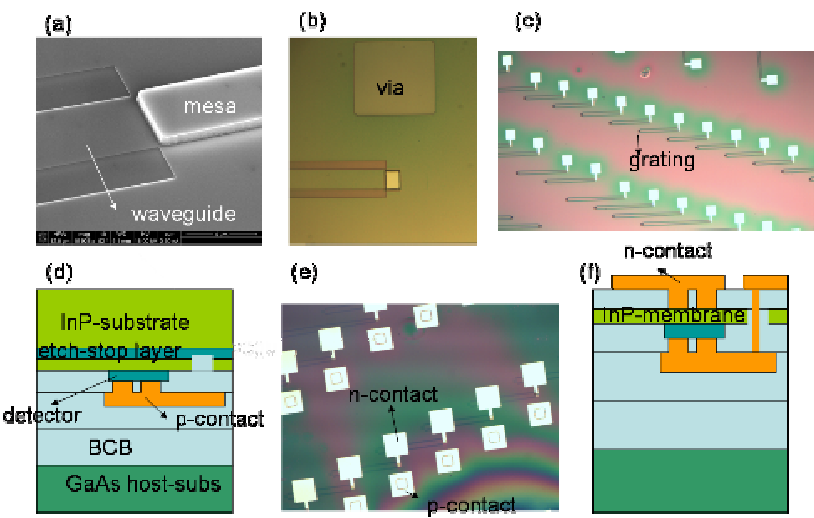

(e)
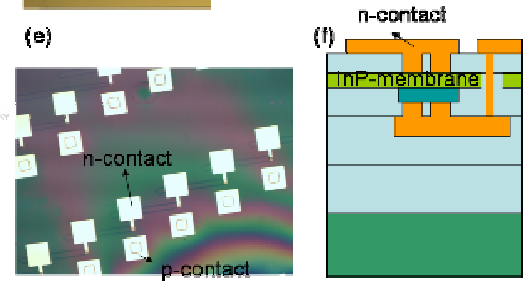

Figure 5. Pictures at different stages of the processing. (a) After InP-etching.

(b) After via-etching. (c) After p-contact metallization. (d) Bonding of the sample. (e) After n-contact metallization. (f) Final detector structure.

The dark current of the detector is a low value of $4 \mathrm{nA}$ at $0.5 \mathrm{~V}$ reverse bias, and the external responsivity (fiber-todetector, using grating couplers) is as much as $0.4 \mathrm{~A} / \mathrm{W}$.

\section{INTEGRATION OF DETECTORS ON INP-MEMBRANE}

We have integrated the demultiplexer from section III with photodetectors. The layout can be seen in Figure 6 and the measured photocurrent at the detectors in Figure 7 . The "trough" in the through-signal is caused by the aggregated dropping of the wavelengths in the channels. Crosstalk values are comparable to the all-optical version. 


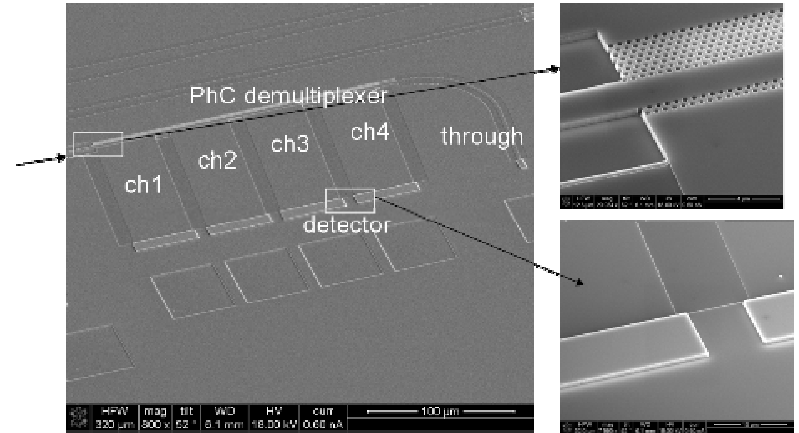

Figure 6. Photonic Crystal demultiplexer with integrated photodetectors (picture prior to bonding).

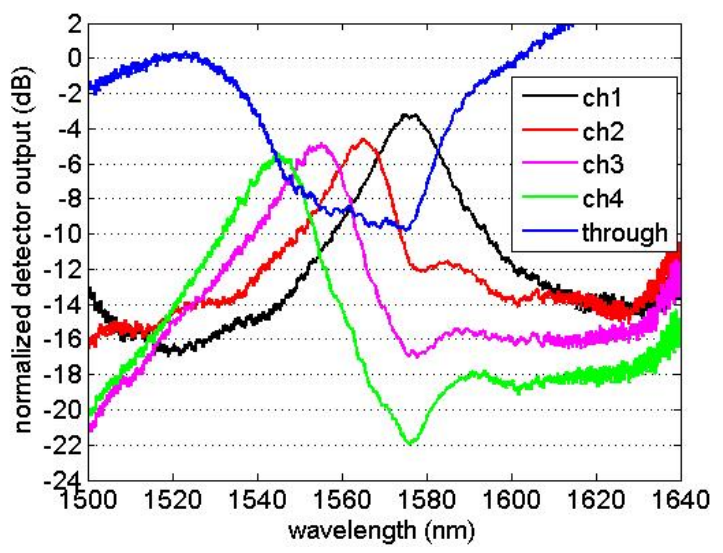

Figure 7. Photocurrent measured at the channel and throug-detectors of the PhC demultiplexer.

\section{POLARIZATION DIVERSITY}

Polarization is hard to tame in nanophotonics. The on-chip optical components are especially polarization sensitive when using high refractive index contrast, so, even when the fiber-tochip coupling can be made polarization independent, the very nanophotonic components cannot. This demands in turn delicate on-chip polarization splitters and rotators. This problem is solved here by implementing polarization diversity. A practical test realization is shown in Figure 8.

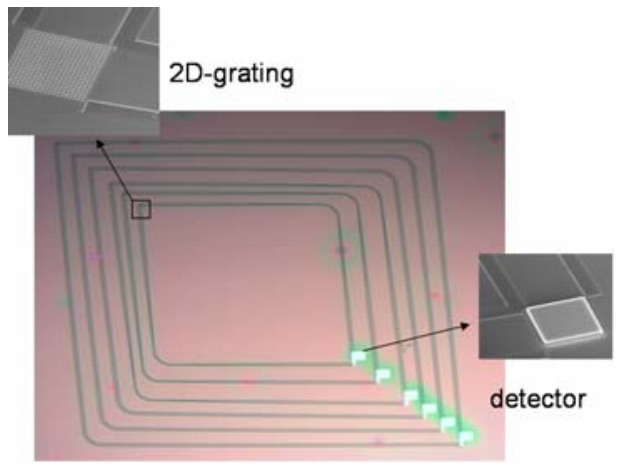

Figure 8. Polarization diversity test from 2D-grating couplers to detectors.
Light from the fiber is again coupled (near) vertically using a 2D-grating. The two orthogonal polarization components are separated at the grating coupler [7] and couple to the TE-mode of their own waveguide. Both arms recombine in the same detector.

The Polarization Dependent Loss is determined by measuring the maximum variation in photocurrent on the detector, when varying the polarization of the input light over all states. This measurement (at the center wavelength of the grating coupler spectrum) is shown in Figure 9, where we measure a PDL of only $0.35 \mathrm{~dB}$.

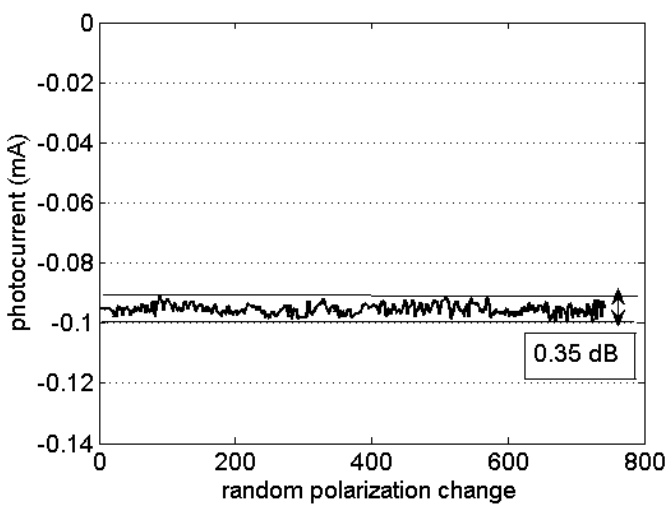

Figure 9. PDL measurement upon random manual changes.

\section{Polarization Diversity PhC DemultipleXer}

In a final demonstration, we have implemented the $\mathrm{PhC}$ demultiplexer in a polarization diversity scheme. The layout is shown in Figure 10. The input light is split in its two orthogonal polarization components at the surface coupler. The demultiplexer is duplicated (one for each polarization) and the channel outputs are measured at a common detector.

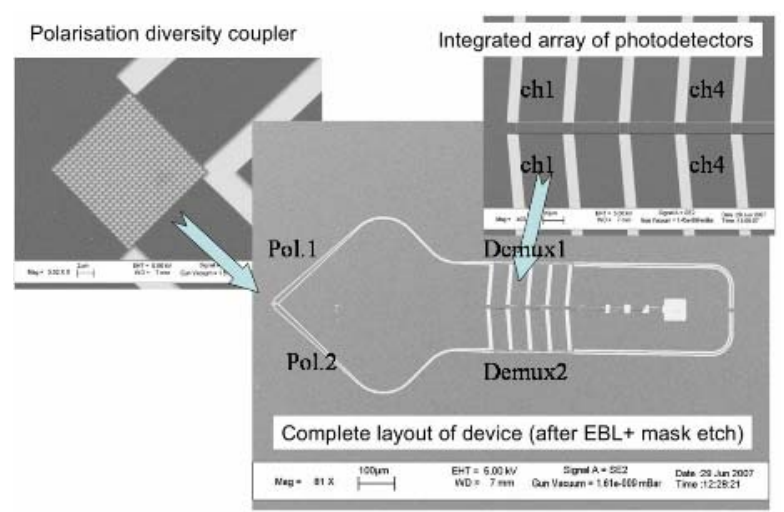

Figure 10. Full chip : Polarization diversity $\mathrm{PhC}$ demultiplexer with integrated photodetectors.

We have measured this device from $\mathrm{CW}$ up to $50 \mathrm{MHz}$ modulation of the input light (higher speeds could not be measured, since we could only use DC probes). The result is shown in Figure 11. 


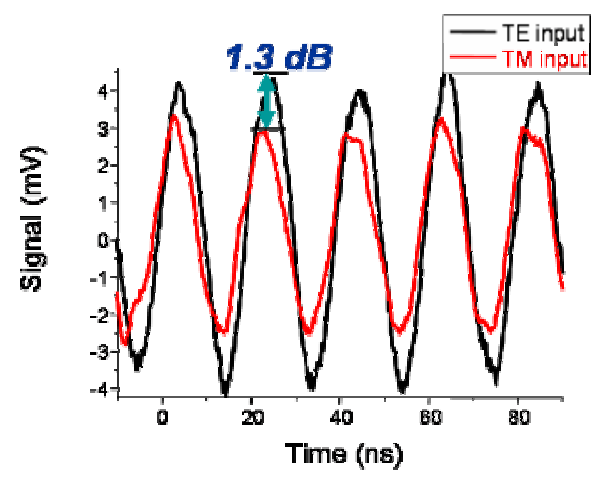

Figure 11. Measurement of the polarization diversity PhC demultiplexer with integrated photodetectors.

The input light was modulated at $50 \mathrm{MHz}$, and the electrical output was measured at the detector channels. The input modulation is clearly followed at the output. For this particular channel, the full chip PDL was still as low as $1.3 \mathrm{~dB}$.

\section{CONCLUSION}

We have demonstrated a grating coupled photonic crystal demultiplexer with integrated detectors on InP-membrane, suited for application in CWDM metro networks. Future work will concentrate on improving the crosstalk of the demultiplexer. Polarization diversity using 2D-grating couplers is used to overcome the polarization sensitivity of the device.

\section{ACKNOWLEDGMENT}

The Fraunhofer Institut fur Nachrichtentechnik, Heinrich Hertz Institut, Berlin, is acknowledged for providing the InP epiwafers. The work was funded by the EU through the FP6IST-004582 FUNFOX project.

\section{REFERENCES}

[1] M. Notomi, A. Shinya, S. Mitsugi, E. Kuramochi and H. Ryu, "Waveguides, resonators and their coupled elements in photonic crystal slabs” Optics Express, vol.12, pp. 1551-1561, 2004.

[2] W. Bogaerts, P. Dumon, D. Van Thourhout, D. Taillaert, P. Jaenen, J. Wouters, S. Beckx and R. Baets, "Compact wavelength-selective functions in Silicon-on-Insulator photonic wires,” J. Selected Topics in Quantum Electronics, vol.12, pp. 1394-1401, 2006.

[3] D. Taillaert, F. Van Laere, M. Ayre, W. Bogaerts, D. Van Thourhout, P. Bienstman, R. Baets, "Grating couplers for coupling between optical fibers and nanophotonic waveguides, ” Jpn. J. Appl. Phys, vol. 45, pp. 6071-6077, 2006.

[4] F. Van Laere, G. Roelkens, M. Ayre, J. Schrauwen, D. Taillaert, D. Van Thourhout, T. F. Krauss, R. Baets, "Compact and highly efficient grating couplers between optical fiber and nanophotonic waveguides, ” Journal of Lightwave Technology, vol. 25, pp. 151-156, Jan 2007.

[5] G. Roelkens, J. Brouckaert, D. Van Thourhout, R. Baets, R. Notzel, and M. Smit, "Adhesive bonding of InP/InGaAsP dies to processed siliconon-insulator wafers using DVS-bis-benzocyclobutene, ” J. Electrochem Soc., vol. 153, G1015-G1019, 2006.

[6] E. Viasnoff-Schwoob, C. Weisbuch, H. Benisty, C. Cuisin, E. Derouin, O. Drisse, G. H. Duan, L. Legouezigou, O. Legoazigou, F. Pommereau, S. Golka, H. Heidrich, H. J. Hensel, and K. Janiak, "Compact wavelength monitoring by lateral outcoupling in wedged photonic crystal multimode waveguides, ” Appl. Phys. Lett., vol. 86, 101107 2005.

[7] D. Taillaert, H. Chong, P. Borel, L. Frandsen, R.M. De La Rue, R. Baets, "A compact two-dimensional grating coupler used as a polarization splitter”, IEEE Photonics Technology Letters, vol. 15, pp. 1249-1251, 2003. 


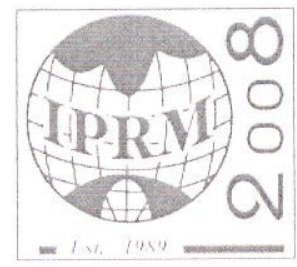

SEARCH

HOME

ABOUT IPRM 2008

COMMITTEES

CONFERENCE PROGRAMME

SHORTCOURSES

PLENARY SESSION

AUTHORS INDEX

PARTNERS AND SPONSORS

CONTACT US
20- INDIUW RHOSRHIDE AND RELATED MATERIALS CONFERENCE 2.) 29 isy 2008 . Versalles - France

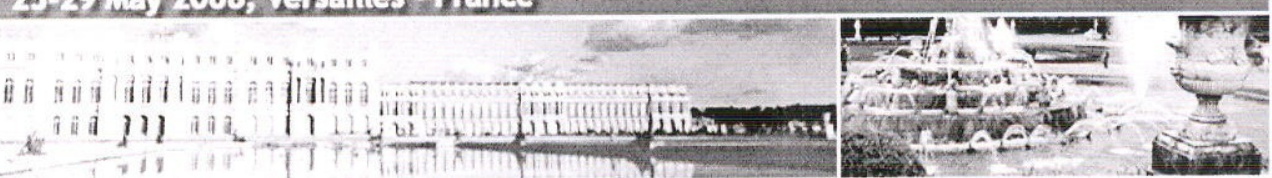

Welcome to the IPRM 2008

20th International Conference on

INDIUM PHOSPHIDE AND RELATED MATERIALS

The 2008 IEEE 20th Conference on Indium Phosphide and Related Materials (IPRM'08) will be held 25-29 May 2008 at Versailles - France. The Lasers and Electro-Optics Society (LEOS) and the Electron Devices Society (EDS) of the Institute of Electrical and Electronic Engineers, Inc. (IEEE) are technical co-sponsors.
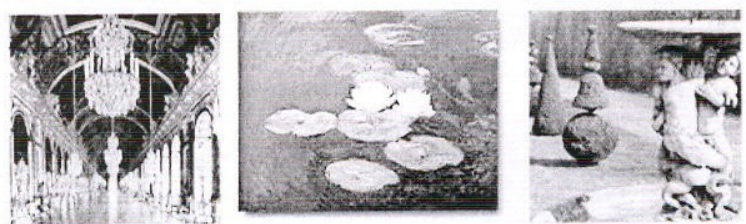

For its 20th edition, IPRM'08 will continue the well-established tradition of bringing together scientists of academic and industrial laboratories and companies to share recent developments in the field of InP and related materials. Contributions will cover topics such as materials, devices, processing and system applications including telecom and datacom defence, sensors, imaging. Emphasis will be put in particular on novel materials and nanostructures, and on hetero-integration emerging techniques.

IEEE Catalog Number : CFP08IIP-CDR

ISBN : $978-1-4244-2259-3$

ISSN : $1092-8669$

organized by

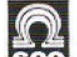

MATOR SPONSORS

CO-OPERATING SOCIETIES

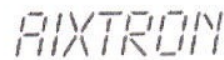

R I B E R

SANDIE
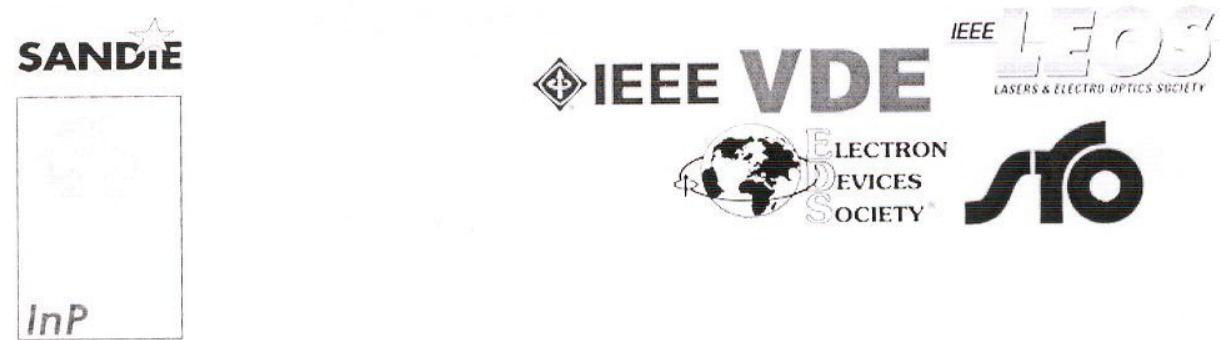

NanoSciences 